\title{
Substituição do feno de tifton pela casca de mamona na dieta de ovinos: componentes não-carcaça
}

[Replacement of tifton hay with castor bean hulls in sheep diet: non carcass components]

\author{
S.A. Urbano ${ }^{1}$, M.A. Ferreira ${ }^{1}$, W.M. Dutra Júnior ${ }^{1}$, R.P.X. Andrade ${ }^{2}$, S.C.R. Félix ${ }^{3}$, \\ J.T.S. Campos ${ }^{3}$, M.C.B. Siqueira ${ }^{3}$ \\ ${ }^{1}$ Universidade Federal Rural de Pernambuco - Recife, PE \\ ${ }^{2}$ Alunos de pós-graduação - Universidade Federal Rural de Pernambuco - Recife, PE \\ ${ }^{3}$ Alunos de graduação - Universidade Federal Rural de Pernambuco - Recife, PE
}

\begin{abstract}
RESUMO
Avaliou-se o efeito da substituição do feno de capim tifton pela casca de mamona, 0, 33, 66 e $100 \%$ na dieta de ovinos, sobre o peso e rendimento dos componentes não constituintes da carcaça e o rendimento de buchada e panelada. Vinte e oito animais não castrados, com sete meses de idade e peso inicial médio de $19,5 \pm 2,45 \mathrm{~kg}$, foram distribuídos em delineamento de blocos ao acaso, com quatro tratamentos e sete repetições, e abatidos após 70 dias de confinamento. Houve decréscimo linear nos pesos da língua $(0,084$ a $0,079 \mathrm{~kg})$, traqueia+pulmão $(0,50$ a $0,42 \mathrm{~kg})$, coração $(0,14$ a $0,12 \mathrm{~kg})$, timo $(0,035$ a $0,025 \mathrm{~kg})$, rins $(0,100$ a $0,088 \mathrm{~kg})$ e peso total dos órgãos $(2,14$ a $1,90 \mathrm{~kg})$ de acordo com o percentual de substituição. $\mathrm{O}$ mesmo comportamento foi verificado para os pesos do esôfago $(0,051$ a $0,045 \mathrm{~kg})$, rúmen-retículo $(0,73$ a $0,64 \mathrm{~kg})$, intestino delgado $(0,78$ a $0,64 \mathrm{~kg})$ e total de vísceras $(2,17$ a $1,92 \mathrm{~kg})$. Para os pesos da cabeça $(1,99$ a $1,66 \mathrm{~kg})$, patas $(0,86$ a $0,73 \mathrm{~kg})$, pele $(2,49$ a $1,99 \mathrm{~kg})$, sangue $(1,36$ a $1,19 \mathrm{~kg})$ e total de subprodutos $(7,12$ a 5,96kg) verificou-se efeito linear negativo de acordo com a substituição. O mesmo foi observado para os pesos de buchada $(4,71$ a $4,22 \mathrm{~kg})$ e panelada $(7,55$ a $6,61 \mathrm{~kg})$. A casca de mamona não deve substituir o feno de capim tifton na dieta de ovinos por causar decréscimo no peso de órgãos, vísceras e subprodutos e influenciar negativamente os pesos e rendimentos de buchada e panelada.
\end{abstract}

Palavras-chave: cordeiro, coproduto, órgãos, quinto quarto, vísceras

\begin{abstract}
The effects of replacing tifton hay with 0, 33, 66 and 100\% of castor bean hulls in the diet of sheep on the non-carcass components of weight and dressing and on the "buchada" and "panelada" yield were evaluated in this research. Twenty-eight non castrated sheep averaging seven months of age and with initial weight of $19.5 \pm 2.45 \mathrm{~kg}$ were assigned to a randomized block design with four treatments and seven replicates, and were slaughtered after 70 days of confinement. A linear decrease of tongue $(0.084$ to $0.079 \mathrm{~kg})$, trachea + lungs $(0.50$ to $0.42 \mathrm{~kg})$, heart $(0.14$ to $0.12 \mathrm{~kg})$, thymus $(0.035$ to $0.025 \mathrm{~kg})$, kidneys $(0.100$ to $0.088 \mathrm{~kg})$ weights and total weight of organs $(2.14$ to $1.90 \mathrm{~kg})$ was observed. The same behavior was observed for the esophagus $(0.051$ to $0.045 \mathrm{~kg})$, rumen-reticulum $(0.73$ to $0.64 \mathrm{~kg})$, small intestine $(0.78$ to $0.64 \mathrm{~kg})$ and total viscera $(2.17$ to $1.92 \mathrm{~kg})$ weights. There was a linear effect for the head (1.99 to $1.66 \mathrm{~kg})$, feet (0.86 to $0.73 \mathrm{~kg})$, skin (2.49 to $1.99 \mathrm{~kg})$, blood (1.36 to $1.19 \mathrm{~kg})$ and total by-products (7.12 to $5.96 \mathrm{~kg}$ ) weights according to the treatments and also for "buchada" (4.71 to $4.22 \mathrm{~kg}$ ) and "panelada" $(7.55$ to $6.61 \mathrm{~kg})$ weights. Castor bean hulls should not replace tifton hay because it decreases the weight of organs, viscera and by-products and adversely affects the "buchada" and "panelada" weight and dressing.
\end{abstract}

Keywords: co-product, lamb, organs, fifth-quarter, viscera

Recebido em 1 de junho de 2011

Aceito em 10 de setembro de 2012

E-mail: stela_antas@yahoo.com.br 


\section{INTRODUÇÃO}

A produção de carne ovina no Nordeste brasileiro desenvolveu-se consideravelmente nos últimos anos. Entretanto, a problemática da escassez de volumosos no período de seca ainda mantém-se como o maior entrave para a atividade. A suplementação alimentar durante esse período tem sido a alternativa encontrada pelos produtores, porém os altos custos não os incentivam. Nesse contexto, os resíduos agroindustriais surgem como ingredientes nutricionais redutores dos custos com a alimentação.

Com o aumento da produção de carcaças, os componentes não constituintes destas são incrementados, sendo necessário que haja um destino adequado proporcionado pela indústria da carne ovina ou por outros segmentos da cadeia produtiva (Medeiros et al., 2008). Segundo Santos et al. (2005), o valor obtido com esses componentes serve para cobrir parte das despesas com o processo de abate, podendo representar em média $16,4 \%$ do preço de venda do animal vivo e $15,9 \%$ do preço da carcaça. A pele, um desses componentes, largamente utilizada e valorizada, quando devidamente processada e manufaturada pela indústria calçadista e vestuária, agrega valores que chegam a superar o preço do animal que a originou (Medeiros et al., 2008).

No Nordeste brasileiro, alguns órgãos e vísceras de ovinos e subprodutos do abate são utilizados, após processamento, no preparo de pratos tradicionais da culinária nordestina, como "buchada", "panelada" e sarapatel, que são bastante apreciados pela população e já consagrados pela cultura popular brasileira (Costa et al., 2010).

No que diz respeito ao valor nutritivo, Madruga et al. (2003) comentaram que as vísceras in natura, obtidas diretamente em abatedouros, apresentam valores de composição centesimal próximos aos dos músculos, verificando-se um elevado teor de proteína para o fígado, em torno de $20 \%$. Os autores citaram ainda que os teores de fósforo e ferro observados em órgãos (coração e fígado) variaram, respectivamente, de 64,87 a $349,57 \mathrm{mg} / 100 \mathrm{~g}$ e de 8,69 a $14,95 \mathrm{mg} / 100 \mathrm{~g}$, compatíveis com o tecido muscular, sendo o pulmão o órgão mais pobre em fósforo.

Objetivou-se avaliar o efeito da substituição do feno de capim tifton pela casca de mamona sobre o peso e rendimento dos componentes não constituintes da carcaça, bem como sobre o rendimento de buchada e panelada de ovinos confinados.

\section{MATERIAL E MÉTODOS}

Foram utilizados 28 ovinos SPRD (sem padrão racial definido), com sete meses de idade e peso inicial médio de $19,5 \pm 2,45 \mathrm{~kg}$, confinados em baias individuais suspensas, com piso ripado, providas de comedouro e bebedouro. Após serem pesados, identificados, submetidos ao controle de endo e ectoparasitas e vacinados contra clostridioses, os animais passaram por um período de adaptação ao manejo e instalações de 30 dias. O arraçoamento foi realizado duas vezes ao dia, às 8 e 15h, na forma de ração completa, com água sempre à disposição dos animais. Diariamente, as sobras foram coletadas e pesadas para ajuste da oferta e cálculo do consumo de matéria seca. As pesagens ocorreram a cada 14 dias, com jejum prévio de sólidos de 16 horas, partindo do início do experimento até o abate.

Para estimativa dos nutrientes digestíveis totais (NDT), realizou-se um ensaio de digestibilidade 40 dias após o início do experimento. Para a estimativa da produção de matéria seca fecal, foi utilizado o marcador externo lignina enriquecida e purificada (LIPE®), por meio de ingestão forçada de uma cápsula de $250 \mathrm{mg} /$ dia, durante sete dias, sendo dois dias para adaptação e cinco dias de coletas de fezes, feitas diretamente da ampola retal, uma vez por dia, às 6, 8, 10, 12 e 14 horas, conforme descrito por Ferreira et al. (2009). O valor estimado do NDT foi calculado com auxílio da equação descrita por por Weiss (1999).

As dietas experimentais foram isoproteicas, sendo a dieta base formulada para atender às exigências para mantença de animais com $24 \mathrm{~kg}$ e permitir ganho de peso médio de $200 \mathrm{~g} \mathrm{dia}^{-1}$, de acordo com as exigências preconizadas pelo NRC (Nutrients..., 1985). As dietas consistiram na substituição do feno de capim tifton pela casca de mamona em 0, 33, 66, 100\% (Tab. 1). 
Tabela 1. Composição percentual e bromatológica das dietas experimentais

\begin{tabular}{|c|c|c|c|c|}
\hline \multirow{2}{*}{ Ingrediente (\%, na MS) } & \multicolumn{4}{|c|}{ Casca de mamona (\%) } \\
\hline & 0 & 33 & 66 & 100 \\
\hline Palma forrageira & 40 & 40 & 40 & 40 \\
\hline Feno de capim tifton & 30 & 20 & 10 & 0,0 \\
\hline Casca de mamona & 0,0 & 9,9 & 19,8 & 29,7 \\
\hline Farelo de soja & 18,5 & 18,5 & 18,5 & 18,5 \\
\hline Milho moído & 10 & 10 & 10 & 10 \\
\hline Cloreto de sódio & 0,5 & 0,5 & 0,5 & 0,5 \\
\hline Mistura mineral & 1,0 & 1,0 & 1,0 & 1,0 \\
\hline Ureia & 0,0 & 0,1 & 0,2 & 0,3 \\
\hline \multicolumn{5}{|c|}{ Composição bromatológica } \\
\hline Matéria seca $(\% \mathrm{MN})$ & 24,99 & 25,01 & 25,02 & 25,04 \\
\hline Proteína bruta (\%MS) & 13,94 & 13,87 & 13,81 & 13,75 \\
\hline Extrato etéreo (\%MS) & 1,60 & 1,51 & 1,41 & 1,31 \\
\hline Matéria mineral (\%MS) & 10,68 & 10,43 & 10,19 & 9,94 \\
\hline Fibra em detergente neutro (\%MS) & 40,49 & 40,23 & 39,96 & 39,70 \\
\hline Fibra em detergente ácido (\%MS) & 16,74 & 17,84 & 18,95 & 20,05 \\
\hline Nutrientes digestíveis totais (\%MS) & 62,61 & 62,49 & 56,60 & 56,11 \\
\hline
\end{tabular}

Decorridos 70 dias experimentais, além do período de adaptação, os animais foram submetidos a uma dieta hídrica e jejum de sólidos por 16 horas. Em seguida, imediatamente antes do abate, foram pesados para obtenção do peso corporal ao abate (PCA). No momento do abate, os animais foram insensibilizados por concussão cerebral, seguida de sangria pela secção da carótida e jugular, sendo o sangue recolhido em recipiente de peso conhecido e posteriormente pesado.

Após esfola e evisceração, foram retiradas a cabeça (secção na articulação atlanto-occipital) e as patas (secção nas articulações carpo e tarsometatarsianas) e registrado o peso da carcaça quente (PCQ), incluindo rins e gordura perirrenal, que foram retirados e pesados após o resfriamento das carcaças por $24 \mathrm{~h}$. O trato gastrointestinal (TGI) foi pesado cheio e vazio para determinação do peso do corpo vazio (PCV).

Os órgãos - língua, traqueia+pulmão, fígado, coração, diafragma, baço, pâncreas, vesícula biliar, testículos + pênis + bexiga + glândulas anexas, rins e timo -, as vísceras - esôfago, rúmen-retículo, omaso, abomaso, intestino delgado e intestino grosso - e os subprodutos sangue, cabeça, patas, pele, gordura interna e gordura perirrenal - foram pesados para mensuração dos componentes não constituintes da carcaça, sendo as vísceras esvaziadas, lavadas e novamente pesadas, para determinação dos rendimentos de buchada e panelada (Silva Sobrinho e Gonzaga Neto, 2001).

Como constituintes da buchada foram considerados: sangue, fígado, rins, pulmões, baço, língua, coração, omento, rúmen, retículo, omaso e intestino delgado (Medeiros et al., 2008). Para panelada foram considerados os constituintes da buchada acrescidos da cabeça e das patas (Clementino et al., 2007).

O delineamento experimental utilizado foi o de blocos ao acaso, sendo os blocos formados de acordo com o peso inicial dos animais. Os dados foram tabulados e posteriormente submetidos à análise de variância e regressão com auxílio do pacote estatístico SAEG (Sistema..., 2007).

\section{RESULTADOS E DISCUSSÃO}

A substituição do feno de capim tifton pela casca de mamona implicou decréscimo linear do consumo de nutrientes digestíveis totais (CNDT), dos pesos da língua, traqueia+pulmão, coração, timo, rins e peso total dos órgãos (PTO), ao passo que não foi observada influência da substituição sobre o consumo de matéria seca (CMS), o peso dos demais órgãos e sobre o rendimento dos órgãos, tanto em relação ao peso corporal ao abate (PCA) quanto ao peso de corpo vazio (PCV) $(\mathrm{P}>0,05)$ (Tab. 2). 
Verificou-se efeito da substituição sobre os pesos do esôfago, rúmen-retículo, intestino delgado e total de vísceras, havendo decréscimo linear de acordo com a porcentagem de substituição do feno pela casca. Os pesos do omaso, abomaso e intestino grosso e o rendimento das vísceras não foram influenciados pela substituição $(\mathrm{P}>0,05)$ (Tab. 3).

Tabela 2. Consumos de matéria seca e nutrientes digestíveis totais, peso e rendimento dos órgãos de ovinos alimentados com casca de mamona em substituição ao feno de capim tifton

\begin{tabular}{|c|c|c|c|c|c|c|c|c|}
\hline \multirow{2}{*}{ Item } & \multicolumn{4}{|c|}{ Casca de mamona (\%) } & \multirow{2}{*}{$\mathrm{CV}$} & \multirow{2}{*}{$\begin{array}{l}\text { Equação de } \\
\text { regressão }\end{array}$} & \multirow{2}{*}{$\mathrm{r}^{2}$} & \multirow{2}{*}{$\mathrm{P}$} \\
\hline & 0 & 33 & 66 & 100 & & & & \\
\hline CMS (kg) & 0,95 & 0,93 & 0,97 & 0,86 & 13,30 & - & - & - \\
\hline CNDT (kg) & 0,64 & 0,63 & 0,60 & 0,52 & 17,45 & $\hat{Y}=0,6634-0,0012 X$ & 0,83 & 0,04 \\
\hline PCA $(\mathrm{kg})$ & 32,84 & 31,59 & 30,37 & 28,67 & 5,32 & $\hat{\mathrm{Y}}=33,358-0,0412 \mathrm{X}$ & 0,99 & 0,0001 \\
\hline Língua (kg) & 0,084 & 0,076 & 0,069 & 0,079 & 7,54 & $\hat{Y}=0,0811-6 \mathrm{E}-05 \mathrm{X}$ & 0,21 & 0,04 \\
\hline Traqueia+pulmão (kg) & 0,50 & 0,50 & 0,43 & 0,42 & 15,62 & $\hat{Y}=0,5021-0,0009 X$ & 0,87 & 0,02 \\
\hline Fígado $(\mathrm{kg})$ & 0,59 & 0,59 & 0,54 & 0,56 & 10,90 & - & - & - \\
\hline Coração (kg) & 0,14 & 0,14 & 0,13 & 0,12 & 15,76 & $\hat{\mathrm{Y}}=0,1463-0,0003 \mathrm{X}$ & 0,97 & 0,007 \\
\hline Diafragma (kg) & 0,12 & 0,13 & 0,10 & 0,11 & 12,91 & - & - & - \\
\hline Baço $(\mathrm{kg})$ & 0,069 & 0,082 & 0,052 & 0,079 & 33,77 & - & - & - \\
\hline Pâncreas (kg) & 0,070 & 0,065 & 0,056 & 0,059 & 20,91 & - & - & - \\
\hline Vesícula Biliar (kg) & 0,022 & 0,015 & 0,010 & 0,017 & 58,38 & - & - & - \\
\hline Sistema reprodutivo $^{1} \mathrm{~kg}$ ) & 0,40 & 0,38 & 0,28 & 0,35 & 28,83 & - & - & - \\
\hline Timo $(\mathrm{kg})$ & 0,035 & 0,033 & 0,036 & 0,025 & 26,02 & $\hat{Y}=0,0349-9 \mathrm{E}-05 \mathrm{X}$ & 0,56 & 0,04 \\
\hline Rins (kg) & 0,10 & 0,098 & 0,090 & 0,088 & 9,67 & $\hat{Y}=0,1005-0,0001 X$ & 0,94 & 0,009 \\
\hline PTO $(\mathrm{kg})$ & 2,14 & 2,10 & 1,80 & 1,90 & 10,19 & $\hat{\mathrm{Y}}=2,1362-0,0031 \mathrm{X}$ & 0,67 & 0,007 \\
\hline PTO : PCA (\%) & 6,56 & 6,66 & 5,96 & 6,61 & 7,63 & - & - & - \\
\hline PTO : PCV $(\%)$ & 6,97 & 7,12 & 6,43 & 7,08 & 7,43 & - & - & - \\
\hline
\end{tabular}

CMS = consumo de matéria seca; CNDT = consumo de nutrientes digestíveis totais; $\mathrm{PCA}=$ peso corporal ao abate; PTO = peso total de órgãos; PCV = peso de corpo vazio

${ }^{1}$ Somatório dos pesos dos testículos, pênis, bexiga e glândulas anexas.

$\mathrm{X}=$ porcentagem de substituição do feno de capim tifton pela casca de mamona.

Tabela 3. Peso e rendimento das vísceras vazias de ovinos alimentados com casca de mamona em substituição ao feno de capim tifton

\begin{tabular}{|c|c|c|c|c|c|c|c|c|}
\hline \multirow{2}{*}{ Item } & \multicolumn{4}{|c|}{ Casca de mamona (\%) } & \multirow{2}{*}{$\mathrm{CV}$} & \multirow{2}{*}{ Equação de regressão } & \multirow{2}{*}{$\mathrm{r}^{2}$} & \multirow{2}{*}{$\mathrm{P}$} \\
\hline & 0 & 33 & 66 & 100 & & & & \\
\hline Esôfago $(\mathrm{kg})$ & 0,051 & 0,046 & 0,044 & 0,045 & 10,11 & $\hat{\mathrm{Y}}=0,0498-6 \mathrm{E}-05 \mathrm{X}$ & 0,72 & 0,02 \\
\hline Rúmen-retículo (kg) & 0,73 & 0,75 & 0,65 & 0,64 & 11,02 & $\hat{Y}=0,751-0,0011 X$ & 0,70 & 0,01 \\
\hline Omaso (kg) & 0,068 & 0,072 & 0,060 & 0,076 & 14,00 & - & - & - \\
\hline Abomaso (kg) & 0,16 & 0,14 & 0,14 & 0,14 & 16,00 & - & - & - \\
\hline Intestino Delgado (kg) & 0,78 & 0,71 & 0,62 & 0,64 & 18,09 & $\hat{Y}=0,7461-0,0015 X$ & 0,83 & 0,02 \\
\hline Intestino Grosso (kg) & 0,39 & 0,33 & 0,36 & 0,38 & 15,29 & - & - & - \\
\hline Total de vísceras (kg) & 2,17 & 2,06 & 1,88 & 1,92 & 11,69 & $\hat{Y}=2,1273-0,0028 X$ & 0,80 & 0,03 \\
\hline Vísceras : PCA (\%) & 6,66 & 6,57 & 6,25 & 6,68 & 9,48 & - & - & - \\
\hline Vísceras : PCV (\%) & 7,07 & 7,04 & 6,74 & 7,15 & 9,54 & - & - & - \\
\hline
\end{tabular}

PCA $=$ peso corporal ao abate; $\mathrm{PCV}=$ peso de corpo vazio.

$\mathrm{X}=$ porcentagem de substituição do feno de capim tifton pela casca de mamona.

Os resultados obtidos podem ser explicados pela diminuição no consumo de energia (Tab. 2) e estão de acordo com Louvandini et al. (2007), ao comentarem que órgãos e vísceras apresentam distintas velocidades de crescimento durante a vida, quando comparados a outras partes do corpo, podendo isso estar relacionado à composição química dos alimentos, especialmente ao teor de energia. Clementino et al. (2007) afirmaram que o peso dos componentes não-carcaça variam de acordo com a quantidade de energia consumida.

Houve decréscimo linear para coração e pulmão, porém Ferreira et al. (2000) afirmaram que tais órgãos mantêm sua integridade, por terem prioridades na utilização de nutrientes, não variando com os níveis de energia. Os dados obtidos estão de acordo com Clementino et al. (2007), que observaram menores pesos para 
coração e pulmão quando a densidade energética da ração foi diminuída.

O fígado, o baço e os rins são órgãos com elevadas taxas metabólicas (Clementino et al., 2007) e seus respectivos tamanhos estão relacionados com o maior consumo de nutrientes pelo animal, especialmente energia e proteína (Ferrel et al., 1976). Com base nessas citações, era esperado decréscimo linear do peso dos referidos órgãos, entretanto apenas observou-se tal efeito para os rins, não sendo verificada influência da substituição sobre os pesos do baço e fígado.

Neste trabalho, à medida que se aumentava a porcentagem de substituição do feno pela casca, elevava-se também o teor de fibra em detergente ácido da dieta; com base nisso, era esperado aumento do peso do rúmen-retículo. $\mathrm{O}$ decréscimo linear do peso desse compartimento nesta pesquisa difere de Santos et al. (2005), ao afirmarem que dietas com menor densidade energética apresentam maiores teores de fibra e menor digestibilidade, aumentando, dessa forma, o tempo de retenção do alimento do rúmen, proporcionando a esse órgão um maior desenvolvimento.

O intestino delgado teve o peso diminuído linearmente quando foram elevadas as porcentagens de substituição do feno pela casca, resultado que também foi observado por Medeiros et al. (2008) ao estudarem percentuais de concentrado, consequentemente de energia, na alimentação de ovinos da raça Morada Nova. Alves et al. (2003) e Oliveira et al. (2002) obtiveram 0,62 e $0,60 \mathrm{~kg}$, respectivamente, como pesos médios para intestino delgado, valores inferiores ao verificado neste trabalho.

$\mathrm{Na}$ Tab. 4, encontram-se os resultados dos subprodutos, sendo verificado decréscimo linear para os pesos da cabeça, patas, pele, sangue e total de subprodutos. A gordura interna, gordura perirrenal e os rendimentos dos subprodutos não foram influenciados pela substituição $(\mathrm{P}>0,05)$.

Tabela 4. Peso e rendimento dos subprodutos de ovinos alimentados com casca de mamona em substituição ao feno de capim tifton

\begin{tabular}{|c|c|c|c|c|c|c|c|c|}
\hline \multirow{2}{*}{ Item } & \multicolumn{4}{|c|}{ Casca de mamona (\%) } & \multirow{2}{*}{$\mathrm{CV}$} & \multirow{2}{*}{$\begin{array}{l}\text { Equação de } \\
\text { regressão }\end{array}$} & \multirow{2}{*}{$\mathrm{r}^{2}$} & \multirow{2}{*}{$\mathrm{P}$} \\
\hline & 0 & 33 & 66 & 100 & & & & \\
\hline Cabeça (kg) & 1,99 & 1,74 & 1,65 & 1,66 & 10,10 & $\hat{Y}=1,9464-0,0032 X$ & 0,77 & 0,002 \\
\hline Patas $(\mathrm{kg})$ & 0,86 & 0,78 & 0,78 & 0,73 & 9,87 & $\hat{Y}=0,8435-0,0012 X$ & 0,88 & 0,008 \\
\hline Pele $(\mathrm{kg})$ & 2,49 & 2,32 & 2,26 & 1,99 & 12,46 & $\hat{Y}=2,5557-0,0047 X$ & 0,94 & 0,005 \\
\hline Sangue (kg) & 1,36 & 1,30 & 1,12 & 1,19 & 10,51 & $\hat{Y}=1,3571-0,002 X$ & 0,70 & 0,008 \\
\hline Gordura interna $(\mathrm{kg})$ & 0,15 & 0,13 & 0,15 & 0,11 & 26,95 & - & - & - \\
\hline Gordura perirrenal $(\mathrm{kg})$ & 0,28 & 0,23 & 0,36 & 0,29 & 31,99 & - & - & - \\
\hline $\begin{array}{l}\text { Total de subprodutos } \\
(\mathrm{kg})\end{array}$ & 7,12 & 6,49 & 6,33 & 5,96 & 8,58 & $\hat{Y}=7,1412-0,0109 X$ & 0,94 & 0,001 \\
\hline Subprodutos: PCA (\%) & 21,66 & 20,53 & 20,81 & 20,85 & 6,24 & - & - & - \\
\hline Subprodutos: PCV (\%) & 23,00 & 21,98 & 22,43 & 22,32 & 6,04 & - & - & - \\
\hline
\end{tabular}

PCA = peso corporal ao abate; $\mathrm{PCV}=$ peso de corpo vazio.

$\mathrm{X}=$ porcentagem de substituição do feno de capim tifton pela casca de mamona.

Esses resultados assemelham-se com os dados obtidos por Siqueira et al. (2001), que observaram maiores pesos para cabeça, patas, pele e sangue em animais abatidos com maiores pesos corporais.

Medeiros et al. (2008) observaram maiores pesos para patas, sangue e pele quando os animais foram submetidos a dietas com densidade energética superior, e não observaram variação para o peso da cabeça. Esses autores também não observaram influência sobre os depósitos adiposos, sendo os resultados semelhantes aos deste experimento. Já Clementino et al. (2007) obtiveram, além do sangue e patas, cabeças mais pesadas para animais que consumiram dietas com maior teor de energia metabolizável. Ao trabalharem com ovinos de três genótipos distintos, submetidos a dietas de alta ou baixa energia, Araújo Filho et al. (2007) verificaram que os animais alimentados com menores níveis energéticos apresentaram menores proporções de patas e pele.

O decréscimo linear para o peso da pele está de acordo com Osório et al. (2001) ao citarem que a 
pele, maior órgão do corpo, desenvolve-se na mesma velocidade do peso vivo e cresce à medida que o animal aumenta de tamanho.

Alves et al. (2003), ao trabalharem com ovinos alimentados com dietas com diferentes densidades de energia metabolizável, abatidos com $33 \mathrm{~kg}$ de peso corporal, encontraram valores muito superiores para gordura interna $(0,620 \mathrm{~kg}-$ valor mínimo encontrado), quando comparados aos valores encontrados neste trabalho $(0,140 \mathrm{~kg}$ - valor médio encontrado). Segundo Gerrard e Grant (2006), o corpo do animal desenvolve-se na seguinte ordem: ossos, músculo e gordura, sendo que o crescimento muscular se dá, em maior velocidade, quando o sistema esquelético já está desenvolvido, e o tecido adiposo, apenas quando o desenvolvimento muscular atinge seu platô, sendo o mais tardio. Os autores ainda evidenciaram que, dos depósitos adiposos, a gordura que ocupa a cavidade corporal é a que se deposita mais precocemente, desde que haja suprimento energético. Assim, como não houve variação na quantidade de gordura interna, é possível inferir que os animais foram abatidos antes de atingirem o pico do desenvolvimento muscular e, consequentemente, antes que a deposição de gordura interna fosse iniciada. Além disso, a pequena quantidade de gordura interna observada deve ser vista como resultado positivo, uma vez que, de acordo com Ferreira $e t$ al. (2000), a gordura interna não é aproveitada para consumo humano, sendo considerada como desperdício de energia alimentar.

Em relação aos pesos da buchada e panelada (Tab. 5), houve diminuição linear para ambos, comportamento que acompanhou a diminuição linear dos pesos dos principais constituintes utilizados para elaborar tais pratos. Os rendimentos de buchada, tanto em relação ao peso corporal ao abate quanto em relação ao peso de corpo vazio, não foram influenciados pela substituição $(\mathrm{P}>0,05)$. Já para os rendimentos de panelada, verificou-se efeito quadrático, com mínimos de $21,7 \%$ e $23,4 \%$ de rendimento em relação ao $\mathrm{PCA}$ e $\mathrm{PCV}$, respectivamente, quando as substituições foram de $57,0 \%$ e $48,0 \%$.

Clementino et al. (2007) encontraram menores pesos para buchada e panelada, porém obtiveram rendimentos semelhantes aos obtidos neste trabalho. Medeiros et al. (2008) também obtiveram números semelhantes para peso e rendimento de buchada, e ainda verificaram redução linear do peso da buchada quando a densidade energética da ração foi menor, assemelhando-se com os dados aqui encontrados.

Tabela 5. Pesos e rendimentos da buchada e panelada de ovinos alimentados com casca de mamona em substituição ao feno de capim tifton

\begin{tabular}{|c|c|c|c|c|c|c|c|c|}
\hline \multirow{2}{*}{ Item } & \multicolumn{4}{|c|}{ Casca de mamona (\%) } & \multirow{2}{*}{$\mathrm{CV}$} & \multirow{2}{*}{ Equação de regressão } & \multirow{2}{*}{$\mathrm{r}^{2}$} & \multirow{2}{*}{$P$} \\
\hline & 0 & 33 & 66 & 100 & & & & \\
\hline Buchada & 4,71 & 4,54 & 4,12 & 4,22 & 9,60 & $\hat{Y}=4,7055-0,0057 \mathrm{X}$ & 0,79 & 0,02 \\
\hline $\begin{array}{l}\text { Rendimento de } \\
\text { buchada : PCA (\%) }\end{array}$ & 14,36 & 14,39 & 13,66 & 14,65 & 7,03 & 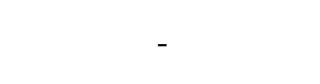 & - & - \\
\hline $\begin{array}{l}\text { Rendimento de } \\
\text { buchada : PCV }(\%)\end{array}$ & 15,25 & 15,41 & 14,72 & 15,68 & 7,03 & - & - & - \\
\hline Panelada & 7,55 & 7,06 & 6,56 & 6,61 & 7,38 & $\hat{\mathrm{Y}}=7,4955-0,01 \mathrm{X}$ & 0,86 & 0,001 \\
\hline $\begin{array}{l}\text { Rendimento de } \\
\text { panelada : PCA }(\%)\end{array}$ & 23,01 & 22,38 & 21,70 & 23,00 & 4,00 & $\begin{array}{c}\hat{Y}=22,969-0,0456 X \\
+0,0004 X^{2}\end{array}$ & 0,82 & 0,01 \\
\hline $\begin{array}{l}\text { Rendimento de } \\
\text { panelada : PCV }(\%)\end{array}$ & 24,44 & 23,96 & 23,39 & 24,61 & 3,89 & $\begin{array}{c}\hat{\mathrm{Y}}=24,353-0,0384 \mathrm{X} \\
+0,0004 \mathrm{X}^{2}\end{array}$ & 0,80 & 0,02 \\
\hline
\end{tabular}

PCA = peso corporal ao abate; $\mathrm{PCV}=$ peso de corpo vazio

$\mathrm{X}=$ porcentagem de substituição do feno de capim tifton pela casca de mamona.

\section{CONCLUSÕES}

A casca de mamona não deve substituir o feno de capim tifton na dieta de ovinos confinados, pois causa decréscimo no peso de órgãos, vísceras e subprodutos, influenciando negativamente os pesos de buchada e panelada. 


\section{REFERÊNCIAS}

ALVES, K.S.; CARVALHO, F.F.R.; FERREIRA, M.A. et al. Níveis de energia em dietas para ovinos Santa Inês: características de carcaça e constituintes corporais. Rev. Bras. Zootec., v.32, p.1927-1936, 2003.

ARAÚJO FILHO, J.T.; COSTA, R.G.; FRAGA, A.B. et al. Efeito de dieta e genótipo sobre medidas morfométricas e não constituintes da carcaça de cordeiros deslanados terminados em confinamento. Rev. Bras. Saúde Prod. Anim., v.8, p.394-404, 2007.

CLEMENTINO, R.H.; SOUZA, W.H.; MEDEIROS, A.N. et al. Influência dos níveis de concentrado sobre os cortes comerciais, os constituintes não carcaça e os componentes da perna de cordeiros confinados. Rev. Bras. Zootec., v.36, p.681-688, 2007.

COSTA, R.G.; MADRUGA, M.S.; SANTOS, N.M. et al. Qualidade físico-química, química e microbiológica da "buchada" caprina, 2010. Disponível em: <http://www.capritec.com.br> Acessado em: 10 dez. 2010

FERREIRA, M.A.; VALADARES FILHO, S.C.; MARCONDES, M.I. et al. Avaliação de indicadores em estudos com ruminantes: digestibilidade. Rev. Bras. Zootec., v.38, p.1568-1573, 2009.

FERREIRA, M.A.; VALADARES FILHO, S.C.; MUNIZ, E.B. et al. Características das carcaças, biometria do trato gastrintestinal, tamanho dos órgãos internos e conteúdo gastrintestinal de bovinos F1 Simental x Nelore alimentados com dietas contendo vários níveis de concentrado. Rev. Bras. Zootec., v.29, p.1174-1182, 2000.

FERRELL, C.L.; GARRET, W.N.; HINMAN, N. Estimation of body composition in pregnant and non pregnant heifers. J. Anim. Sci., v.42, p.1158-1166, 1976.

GERRARD, D.E.; GRANT, A.L. Principles of animal growth and development. Revised Printing. Purdue University, E.U.A.: Kendall/Hunt Publishing Company, 2006. 264p.

LOUVANDINI, H.; NUNES, G.A.; GARCIA, J.A.S. et al. Desempenho, características de carcaça e constituintes corporais de ovinos Santa Inês alimentados com farelo de girassol em substituição ao farelo de soja na dieta. Rev. Bras. Zootec., v.36, p.603609, 2007.
MADRUGA, M.S.; REZER, J.S.; PEDROSA, N.A. Caracterização química e microbiológica de vísceras caprinas destinadas ao preparo de buchada e picado. Rev. Nac. Carne, v.18, p.36-45, 2003.

MEDEIROS, G.R.; CARVALHO, F.F.R.; FERREIRA, M.A. et al. Efeito dos níveis de concentrado sobre os componentes não-carcaça de ovinos Morada Nova em confinamento. Rev. Bras. Zootec., v.37, p.1063-1071, 2008.

NUTRIENTS requeriments of sheep-NRC. 6th ed. Washington, D.C.: National Academy Press. 1985. 99p.

OLIVEIRA, M.V.M.; PÉREZ, J.R.O.; ALVES, E.L. et al. Avaliação da Composição de Cortes Comerciais, Componentes Corporais e Órgãos Internos de Cordeiros Confinados e Alimentados com Dejetos de Suínos. Rev. Bras. Zootec., v.31, p.1459-1468, 2002.

OSÓRIO, M.T.M.; OSÓRIO, J.C.S.; JARDIM, R.D. et al. Desenvolvimento de cordeiros da raça corriedale criados em distintos sistemas. Rev. Bras. Agroc., v.7, p.46-49, 2001.

SANTOS, N.M.; COSTA, R.G.; MEDEIROS, A.N. et al. Caracterização dos componentes comestíveis não constituintes da carcaça de caprinos e ovinos. Agrop. Tec., v.26, p.77-85, 2005.

SILVA SOBRINHO, A.G.; GONZAGA NETO, S. Produção de carne caprina e cortes da carcaça, 2001. Disponível em: <http://www.sheepembryo.com.br/ artigos.php> Acessado em: 04 jan. 2011.

SIQUEIRA E.R.; SIMÕES, C.D.; FERNANDES, S. Efeito do sexo e do peso ao abate sobre a produção da carne de cordeiro. Morfometria da carcaça, peso dos cortes, composição tecidual e componentes não constituintes da carcaça. Rev. Bras. Zootec., v.30, p.1299-1307, 2001.

SISTEMA de análises estatísticas e genéticas - SAEG. Viçosa, MG: UFV, 2007. 301p.

WEISS, W. Energy prediction equations for ruminant feeds. In: CORNELL NUTRITION CONFERENCE FOR FEED MANUFACTURERS, 61., 1999, Ithaca. Proceedings... Ithaca: Cornell University, 1999, p.176-185. 